\title{
The temperature distribution during heating in hot plate welding process
}

\author{
Krzysztof Wałęsa ${ }^{1, *}$, Ireneusz Malujda ${ }^{1}$, Jan Górecki ${ }^{1}$, and Dominik Wilczyński ${ }^{1}$ \\ ${ }^{1}$ Chair of Basics of Machine Design, Poznan University of Technology, Piotrowo 3 Street, 60-965 \\ Poznan, Poland
}

\begin{abstract}
Most of the industrial machines use the belt transmission for the power transfer. These mechanisms often use the round belts with a few millimetres in diameter, which are made of the thermoplastic elastomers, especially the polyurethane. Their production process requires the bonding step, which is often performed by the butt welding, using the hot plate. To design the automatic welding machine in a proper way, the authors analyzed this process. One of the most important parameter which describes the hot plate welding is plasticized distance. Knowledge about its value is necessary to predict the length reduction of the belt during welding and will be used during the quality of the joint rating. To obtain value of this parameter the temperature distribution calculations are needed. The paper shows the results of the analytical calculations of the temperature distribution and their comparison with analyses performed by the FEM implements. Calculations were performed for the thermoplastic elastomer during the heating phase in the hot plate welding process.
\end{abstract}

Keywords: hot plate welding, temperature distribution, FEM analysis, conduction, convection, radiation

\section{Introduction}

Loops of flexible material, including conveyor and power transmission belts are, owing to their behaviour, commonly used in machine engineering. Conveyor belts are most often made of composite materials, consisting of polystyrene or polyurethane matrix reinforced with steel, aramid or polyester fibres [1,2]. Besides conventional conveyor belts there are also perforated belts used in light-duty vacuum conveying systems [3]. In the group of power transmission belts the most popular are flat and toothed (timing) belts and belts with nonrectangular cross-section (including in particular V-belts and round belts). Flat belts are used predominantly where relatively high linear speeds of the intermediate link are desired. Timing belts, in turn, are used both in simple drives and in non-conventional systems, such as variable ratio transmissions [4-6]. Belts with a non-rectangular cross-section, in particular V-belts and round belts, the types commonly used in power transmission applications, are made of rubber, rubber composite and polyurethane or polyester based elastomers [7-9].

\footnotetext{
* Corresponding author: krzysztof.walesa@put.poznan.pl

Reviewers: Andrzej Kołodziej, Ján Vavro
} 
Elastomeric belts with a non-rectangular cross-section are often made of polyurethane $[8,9]$. The efficiency of this process (most often performed in two phases) [10] is of essence especially when we take into account its vast popularity in industrial applications. In the first phase a long strip of belting material is produced which is next cut to length and looped by firmly connecting the ends $[8,9]$. In most cases the belt ends are butt welded with a hot plate. This process is relatively cheap and uses a relatively simple technology [11]. Butt welding of polymeric materials is commonly used in industrial and civil engineering sectors. This technique has been in use for many years now for bonding items such as reservoirs of vehicle fluids, lamp enclosures, engine auxiliaries [12] and pipes [13]. A number of research projects have been carried out concerning welding of different polymeric materials, including acrylonitrile butadiene styrene (ABS) [14], methyl polymethacrylate (PMMA) [15], polycarbonate (PC) [16] and also polypropylene (PP) [17].

The authors of this paper started a research project to design an appliance for automatic hot-plate butt welding of belts [9]. In order to verify the design assumptions the process was analysed to investigate the effect of the process parameters on the quality of the obtained joint. Polyurethane TPU C85A, a commonly available belting material $[13,18]$ was chosen for the research. According to a review of the available literature, the previous research projects concerned mainly high stiffness polymers [11-17]. On the other hand, information on the application of this technique for joining thermoplastic elastomers, in particular polyurethane can hardly be found. The planned examinations of the butt welding process require investigation of the thermomechanical phenomena taking place during the process, including determination of the temperature distribution pattern during heating of the belt to be joined. This will enable us to determine the depth of the plastic region (plasticized distance). Next we can determine the loss of length during the heating process and identify the weld flaws [19].

The temperature distribution pattern resulting from the interaction between the hot plate and the belt end being heated has been predicted in literature sources. These predictions are generally based on a model in which one side of a rectangular prism is heated up with a precisely defined heat flux density $[11-14,20,21]$. In our opinion this approach is not suitable for analyses of this kind performed for belt welding processes to be used on an industrial scale.

\section{Theoretical background of the heating phase of the hot plate butt welding process}

The hot plate welding process applied for joining of belts comprises 5 phases [21, 22]. These are: squaring the mating surfaces on the heated plate, heat soak phase, plate removal, pressing the ends against each other and, finally, cooling down. The whole process takes from a few seconds up to over a dozen minutes [23].

The first two phases are very similar in terms of the thermodynamic processes taking place. For this reason, they can be considered together and referred to by a single term: belt heating phase (Fig. 1, A and B). The primary aim of this process is to transfer heat from the heating tool to the belting material. As a result, the mating surfaces are activated for the subsequent physical/chemical processes which are critical for the quality of the joint [12].

The heating process (A) starts by moving the belt ends (1) held by clamps (2) towards the hot plate (3) with speed $v_{m}$. As soon as the surfaces have been brought into contact, the belt end is pressed against the plate with force $F_{m}$. This is the bead-up phase in which some amount of the belting material becomes mouldable and a bead is formed on the perimeter when the end face is pressed against the hot plate. This is a very important step in which the mating surfaces are squared against the hot plate, this minimising the risk of joint flaws. 
During the heat soak phase (B) the belt ends are pressed against the hot plate with a smaller force $F_{h}$ as compared the force applied in the bead-up phase.
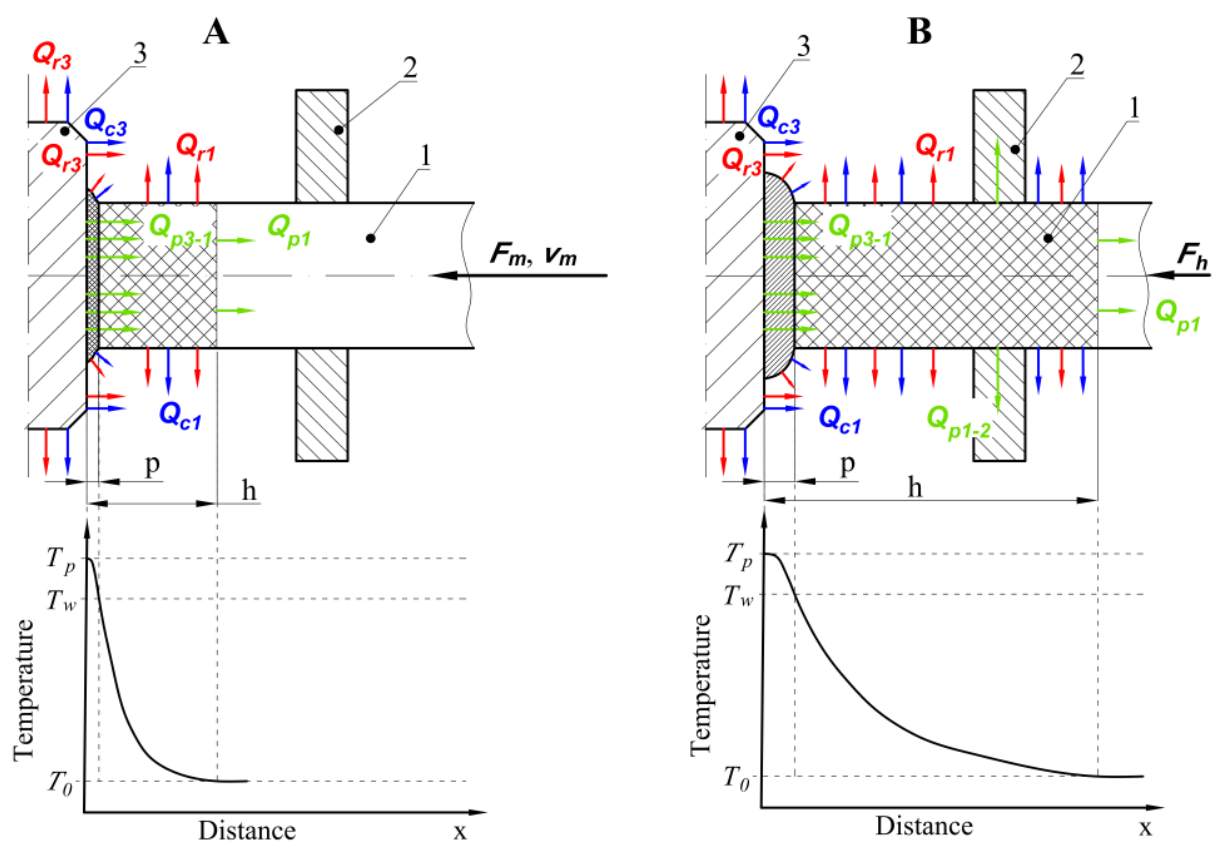

Fig. 1. The expected distribution of temperature during the hot plate welding process: A - squaring (bead-up) phase, B - heat soak phase; 1 - belt, 2 - holder, 3 - hot plate, $F_{m}$ - bead-up force, $v_{m}$ - matching (squaring) speed, $T_{p}$ - hot plate temperature, $T_{w}$ - welding temperature, $T_{0}$ - ambient temperature, $p$ - depth of plastic region, $h$ - depth of heat penetration; $Q_{p 3-1}, Q_{p l}, Q_{r l}, Q_{r 3}, Q_{c l}, Q_{c 3}-$ heat flux densities [22]

The hot plate temperature is maintained at the value of $T_{p}$ which is higher than both the welding temperature $T_{w}$ and the melting point of the work piece material $T_{t}$. For amorphous or network polymers the last of these values is somewhat indefinite as these materials melt over a certain temperature range rather than at a specific melt point $[24,25]$. The hot plate temperature $T_{p}$ must be carefully chosen, such that the welding temperature $T_{w}$ is maintained throughout the mating surface of the belt (loss of energy caused by thermal contact resistance at the plate and belt interface must be taken into account) without causing thermal deterioration of plastic [26].

Heating of the mating face results in a gradual increase of the temperature along the belt axis. As such, the following zones can be identified:

- $p$ - in which material is heated up above $T_{w}$,

- $h$ - in which material is heated up above $T_{0}$.

The heating process involves various heat conduction phenomena, including conduction by thermal contact at the plate/belt interface, heat conduction along the belt axis, free convection and, finally, heat radiation. In the heating process under analysis we can distinguish the following heat fluxes (Fig. 1, A and B):

- $Q_{p 3-1}-$ transferred at the plate/belt interface,

- $Q_{p 1}$ - transferred through the belt body,

- $Q_{c 3}$ and $Q_{c l}$ - released to the surroundings through natural convection by the hot plate and by the belt,

- $Q_{r 3}$ and $Q_{r l}$ - released to the surroundings through radiation by the hot plate and by the belt,

- $Q_{p l-2}$ - transferred to the belt holders by thermal contact conduction. 
The thermal contact conductance at the belt and plate interface and heat conduction through the belt body are the most important phenomena from the point of view of heat exchange. Due to low process temperatures (the maximum being $300^{\circ} \mathrm{C}$ ) the amount of heat transferred by radiation has a minor share in the total heat exchange and, as such, it will be ignored in the further part of this analysis. Moreover, the transfer of heat by convection will also be omitted at this stage due to problems with estimating the values of convective heat transfer coefficient and hardly attainable in industrial conditions repeatable temperature of the surroundings [27].

The belt ends are matched (squared) by slightly melting the mating surfaces against the hot plate. This reduces the probability of joint flaws and ensures consistent heat transfer conditions at the belt and plate interface (Fig. 2) [28]. The amount of heat transferred by the thermal contact conduction - at the surface peaks $\left(Q_{p 3-1}\right)$, by convection - through empty spaces filled with hot air $\left(Q_{c 3}\right)$ and by radiation $\left(Q_{r 3}\right)$ will be substituted with the equivalent contact heat conduction adopted for the entire surface $\left(Q_{p 3-1}\right)$. This makes the heat exchange conditions more predictable, at the same time enhancing the process efficiency. As a result, the effect of thermal contact resistance, a phenomenon causing problems in modelling, is at least reduced or even eliminated. These problems result from a number of different mathematical models to choose from, and different parameters relating to the material properties and the quality of interacting surfaces taken into account in them [29]. The observable effect of the thermal contact resistance is an abrupt drop of temperature across the interface of the two bodies in contact $[30,31]$.

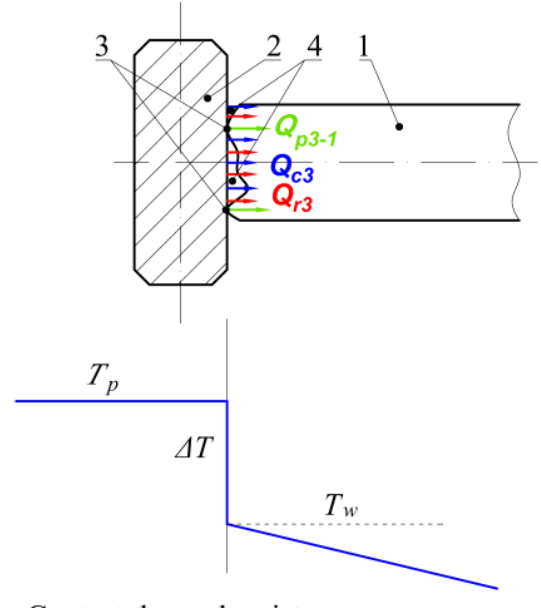

Contact thermal resistance

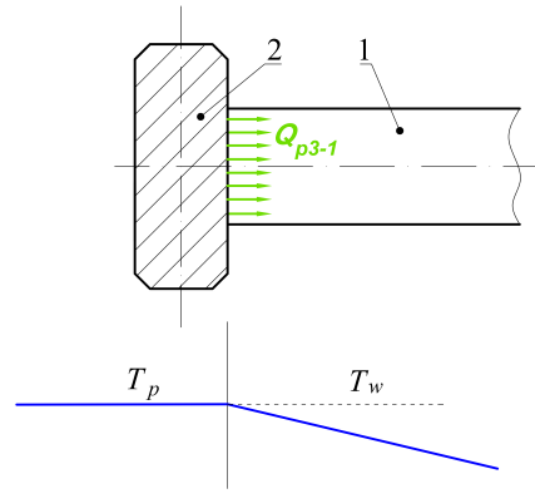

Ideal contact conductance

Fig. 2. Heating of squared and non-squared mating surface of belt: 1 - belt, 2 - hot plate, 3 - contact points, 4 - voids (filled with hot air); $Q_{p 3-1}, Q_{p l}, Q_{r l}, Q_{r 3}, Q_{c l}, Q_{c 3}$ - heat fluxes; $T_{w}$ - welding temperature, $T_{p}$ - hot plate temperature, $\Delta T$ - temperature difference

In the heat soak phase the plastic region ( $p$ distance) should be increased as required to ensure appropriate jointing conditions. The side effects of heating include expansion of the heat penetration zone (distance $h$ ) and initiation of heat transfer to holders ( $Q_{p l-2}$ on Fig. 1 B).

\section{Temperature distribution determination methodology}

For a complete analysis of the hot plate butt welding process it is necessary to determine the distribution of temperature, i.e. the relationship between the temperature values at a finite 
number of points of the heated area and the heating time [27]. To this end analytical computations were carried out, followed by FEM validation of their results.

\subsection{Assumptions to the temperature distribution computations}

The temperature distribution during heating of the belt is determined by solving the following thermal conductance equation [27]:

$$
\frac{\partial}{\partial x}\left(\lambda \frac{\partial T}{\partial x}\right)+\frac{\partial}{\partial y}\left(\lambda \frac{\partial T}{\partial y}\right)+\frac{\partial}{\partial z}\left(\lambda \frac{\partial T}{\partial z}\right)+q_{v}=c_{p} \cdot \rho \cdot \frac{\partial T}{\partial t} .
$$

where: $\lambda$ - thermal conductivity of the belting material $\left[\frac{\mathrm{w}}{\mathrm{m} \cdot \mathrm{K}}\right] ; \rho-$ density of the plastic $\left[\frac{\mathrm{kg}}{\mathrm{m}^{3}}\right]$; $c_{p}$ - specific heat at a constant pressure $\left[\frac{\mathrm{J}}{\mathrm{kg} \cdot \mathrm{K}}\right] ; q_{v}$ - amount of heat generated inside the material $[\mathrm{W}] ; T$-temperature $[\mathrm{K}] ; t$ - time $[\mathrm{s}] ; x, y, z$-rectangular coordinates.

It would be a challenging task for a general case situation. Therefore, the following assumptions can be made for the purpose of this analysis:

- heat is transferred in non-stationary, unsteady state conditions,

- the belt is a semi-infinite body with a high value of the length-to-diameter ratio and isotropic properties of the material,

- during initial heating heat is transferred solely from the flat face,

- heat exchange by convection and radiation are ignored,

- heat is not generated in the body of material,

- the hot plate temperature is constant and uniform over the entire surface,

- the values of density, specific heat and thermal conductivity are constant and independent of the temperature,

- thermal expansion of the material is omitted.

Under the above assumptions the problem boils down to one-dimensional transfer of heat. In order to obtain realistic results the input values given in Table 1 were used.

Table 1. Input values used for determination of the temperature distribution in the belt during heating

\begin{tabular}{|c|c|c|}
\hline Property & Value: & Source: \\
\hline Density $\rho\left[\frac{\mathrm{kg}}{\mathrm{m}^{3}}\right]$ & 1168 & \multirow{3}{*}{ [18] } \\
\hline Specific heat at constant pressure $c_{p}\left[\frac{\mathrm{J}}{\mathrm{kg} \cdot \mathrm{K}}\right]$ & 1700 & \\
\hline Thermal conductivity $\lambda\left[\frac{\mathrm{W}}{\mathrm{m} \cdot \mathrm{K}}\right]$ & 0.21 & \\
\hline Hot plate temperature $T_{p}[\mathrm{~K}]$ & 300 & $\begin{array}{c}\text { Own } \\
\text { assumption }\end{array}$ \\
\hline Ambient temperature $T_{0}[\mathrm{~K}]$ & 20 & $\begin{array}{c}\text { Own } \\
\text { assumption }\end{array}$ \\
\hline Melting point $T_{m}[\mathrm{~K}]$ & 210 & {$[18]$} \\
\hline $\begin{array}{l}\text { Thermal contact conductance assuming the presence of } \\
\text { thermal contact resistance, } h\left[\frac{\mathrm{W}}{\mathrm{m}^{2} \cdot \mathrm{K}}\right]\end{array}$ & 2 & {$[30,31]$} \\
\hline $\begin{array}{l}\text { Thermal contact conductance assuming perfect thermal } \\
\text { contact, } h\left[\frac{\mathrm{W}}{\mathrm{m}^{2} \cdot \mathrm{K}}\right]\end{array}$ & $\infty$ & {$[30,31]$} \\
\hline Time span of analysis $t$ [sec.] & $1-180$ & $\begin{array}{c}\text { Own } \\
\text { assumption }\end{array}$ \\
\hline Melting depth to ensure perfect thermal contact $p[\mathrm{~mm}]$ & 0.2 & $\begin{array}{c}\text { Own } \\
\text { assumption }\end{array}$ \\
\hline
\end{tabular}

Three cases were considered:

- perfect thermal conduction conditions during the whole period of heating (ID), 
- thermal contact resistance during the initial heating period until the plastic region reaches the distance of $p=0.2 \mathrm{~mm}$ when ideal conduction conditions are obtained (SR),

- thermal contact resistance during the whole period of heating (may be caused, for example, by gasses emitted by the melting material) (WR).

\subsection{Analytical calculations}

Under the above simplifying assumptions the above equation (1) takes the following form:

$$
a \cdot \frac{\partial^{2} T}{\partial x^{2}}=\frac{\partial T}{\partial t}
$$

where: $a$ is the thermal diffusivity $\left[\frac{\mathrm{m}^{2}}{\mathrm{~s}}\right]$.

The heated body can be assumed to be semi-infinite under the following condition [27]:

$$
\text { Fo } \ll 1 .
$$

This condition will be applied in the heating case under analysis.

Let us assume that the following boundary-initial conditions hold:

$$
T(x, 0)=T_{0} \quad \vee \quad T(0, t)=T_{p} \quad \vee \quad T(\infty, t)=T_{0},
$$

and use the Laplace transform to obtain solution for infinite halfspace expressed as follows:

$$
T(x, t)=T_{p}+\left(T_{0}-T_{p}\right) \cdot \operatorname{erf}\left(\frac{x}{2 \cdot \sqrt{a \cdot t}}\right) .
$$

This yields the function representing the relationship between the temperature and time $t$ and co-ordinate $x$ along the belt axis. Note that this approach ignores the phase change of the heated material during softening and melting. For describing this phase change it would be necessary to know the melting point $T_{t}$ and the phase change enthalpy. The material does not exhibit a clear cut melting temperature as shown by the tests performed by the authors and, as such, figuring out the enthalpy of melting will be still less practicable [24]. For this reason, melting is ignored at this stage of modelling of the welding process. The softening temperature adopted for the purpose of the calculations is an indicative value, taken from the range given by the supplier of the testing material [18].

\subsection{FEM modelling}

The results of the performed analytical calculations were verified using finite element method under Abaqus environment. To this end a 3D axially symmetric hot plate model was generated $(20 \mathrm{~mm}$ in diameter by $5 \mathrm{~mm}$ thick). The belt, in turn, was modelled as a linear element ( $20 \mathrm{~mm}$ long by $4 \mathrm{~mm}$ in diameter). The values of the belt material properties were the same as the calculation input values (Table 1) and the hot plate was assumed to be made of steel. The finite element model, showing the finite element grid, is displayed in Fig. 3.

The analyses were carried out for three cases of heat transfer between the hot plate and the belt. Therefore, the analysis was performed as follows:

- for the case of perfect thermal conduction conditions (ID): for infinitely high thermal contact conductance $(h=\infty)$ throughout the whole period under analysis,

- for the case in which thermal contact resistance occurs during the entire heating process (WR): thermal contact conductance of $h=2\left[\frac{\mathrm{W}}{\mathrm{m}^{2} \cdot \mathrm{K}}\right]$, for the whole time period under analysis, - for the case with thermal contact resistance occurring only in the initial part of the heating process (SR): 
1) thermal contact conductance of $h=2\left[\frac{\mathrm{W}}{\mathrm{m}^{2} \cdot \mathrm{K}}\right]$ for the period of $t=2.55$ [sec.] (till the plastic region has reached the distance of $p=0.2[\mathrm{~mm}]$ ),

2) after that time and till the end of the heating process: $h=\infty$.

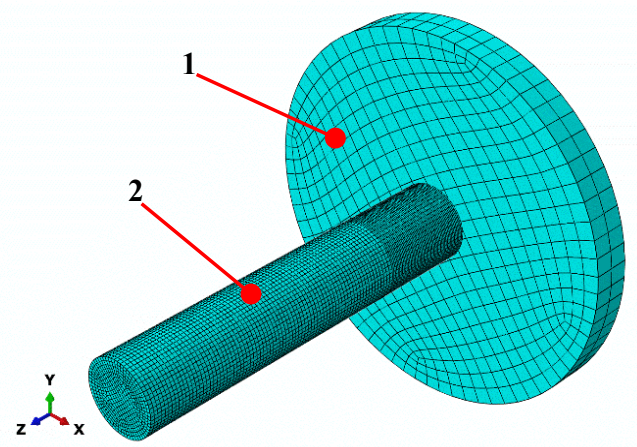

Fig. 3. Finite element model used for the temperature distribution analysis: 1 - belt, 2 - hot plate

The calculations were carried out for twenty seven heating time periods in the range of $1-180 \mathrm{sec}$.

\section{Results and discussion}

Fig. 4 presents the selected results of the analytical and numerical calculations of the temperature distribution during heating for the case of perfect thermal contact between the belt and hot plate during the entire heating time period (ID).

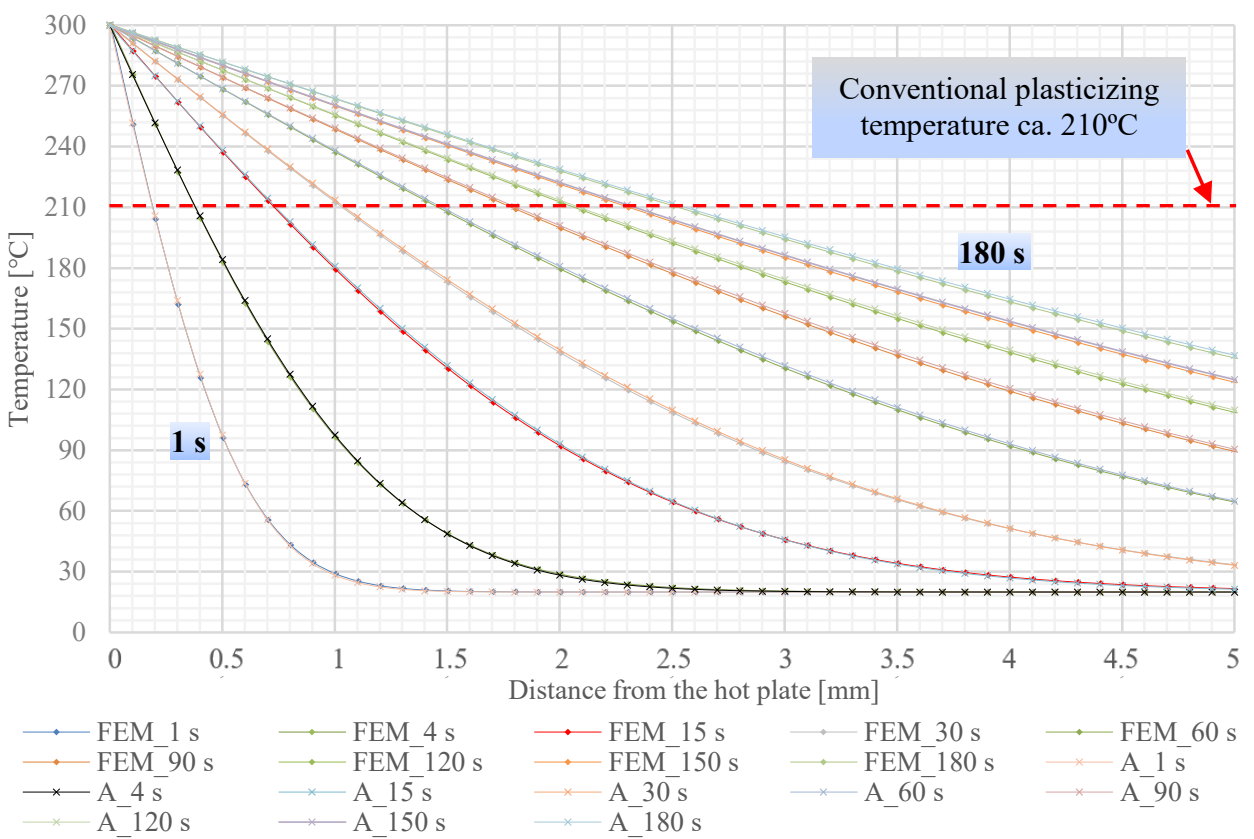

Fig. 4. Relationship between the temperature and the distance from the hot plate at different points in time for the case of perfect thermal contact conditions. FEM_.. - FEM results, A_... - analytical results 
The results of analytical and numerical calculations are very similar with the differences between the respective values increasing over time.

Fig. 5 presents a comparison of selected temperature distribution curve for all the cases of thermal contact conduction conditions for the times in the range of 8-160 sec.

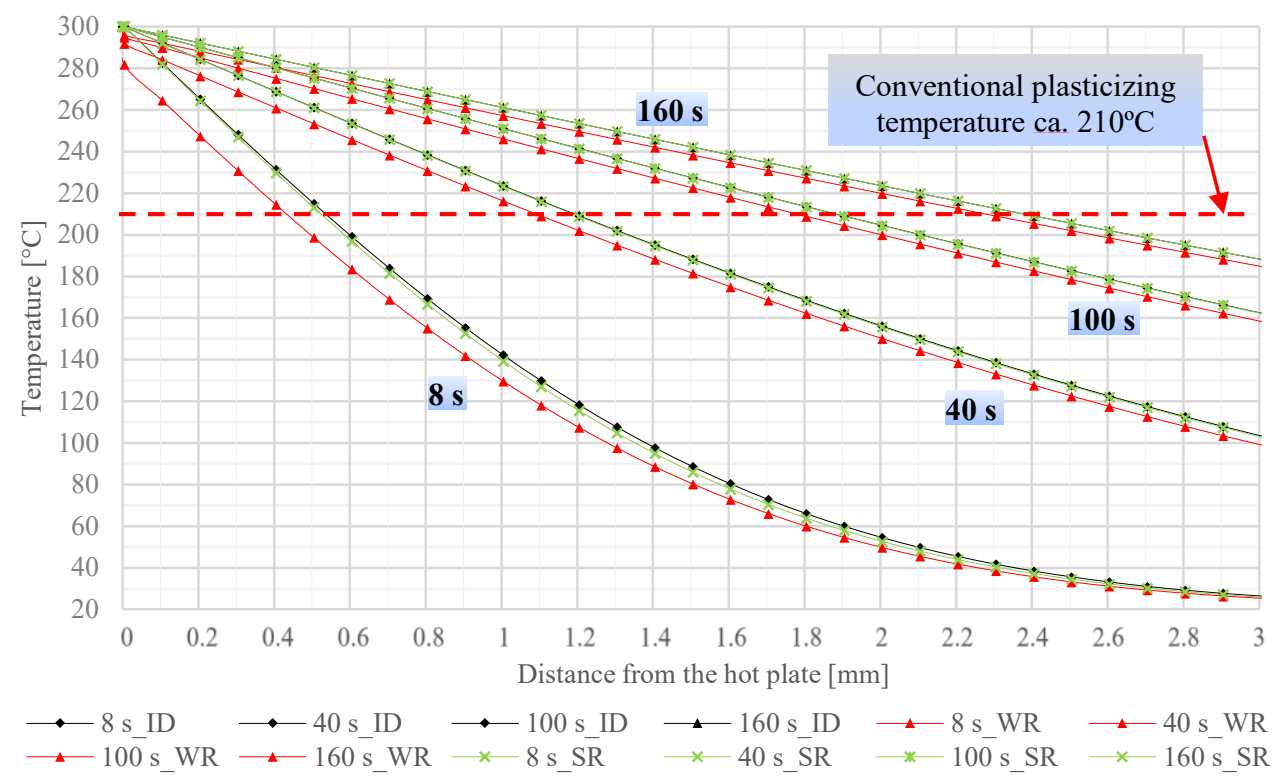

Fig. 5. The relationship between the temperature and the distance from the hot plate at different points in time for the case of perfect thermal contact conditions. .... ID - perfect thermal contact, ..._SR thermal contact resistance in the initial period of heating only, ..._WR - thermal contact resistance throughout the heating process

The temperature distribution varies depending on the adopted thermal conduction model at the hot plate or belt interface. For the case in which thermal resistance occurs during the entire heating process (WR) a considerable drop of temperature is noted at the subsequent points along the belt. This is caused, inter alia, by the sudden drop of temperature at the mating face of the belt directly touching the hot plate. This drop is so big that the temperatures do not equalise even after long heating (180 sec.).

A slightly different result is obtained when we compare the case of heating under perfect thermal contact conditions (ID) with the case assuming thermal contact resistance limited to the initial softening period (WR i.e. before the plastic region has reached the distance of $p=0.2 \mathrm{~mm}$ ). For small heating times (up to $60 \mathrm{sec}$.) different temperature distributions are obtained. When thermal resistance is included during the initial heating phase, the temperatures will slightly decrease at the analysed points. The distributions equalise when the heating time is increased (to over $60 \mathrm{sec}$.) as the belt gets sufficiently heated up owing to the long-time of heat conduction under ideal thermal contact conditions.

Fig. 6 presents the relationship between the plastic region depth and the heating time. The increase of the depth of plastic region over time is represented by a nonlinear curve. Note, however, that the growth rate decreases as the heating proceeds. As such, the depth of the plastic region will not increase in proportion to the increase in the heating time. Analysing this relationship and the temperature distributions over time (Fig. 4 and Fig. 5) we can see that increasing of the heating temperature could be a more efficient way to increase the depth of plastic region (plasticized distance) as compared to a longer heating time. 


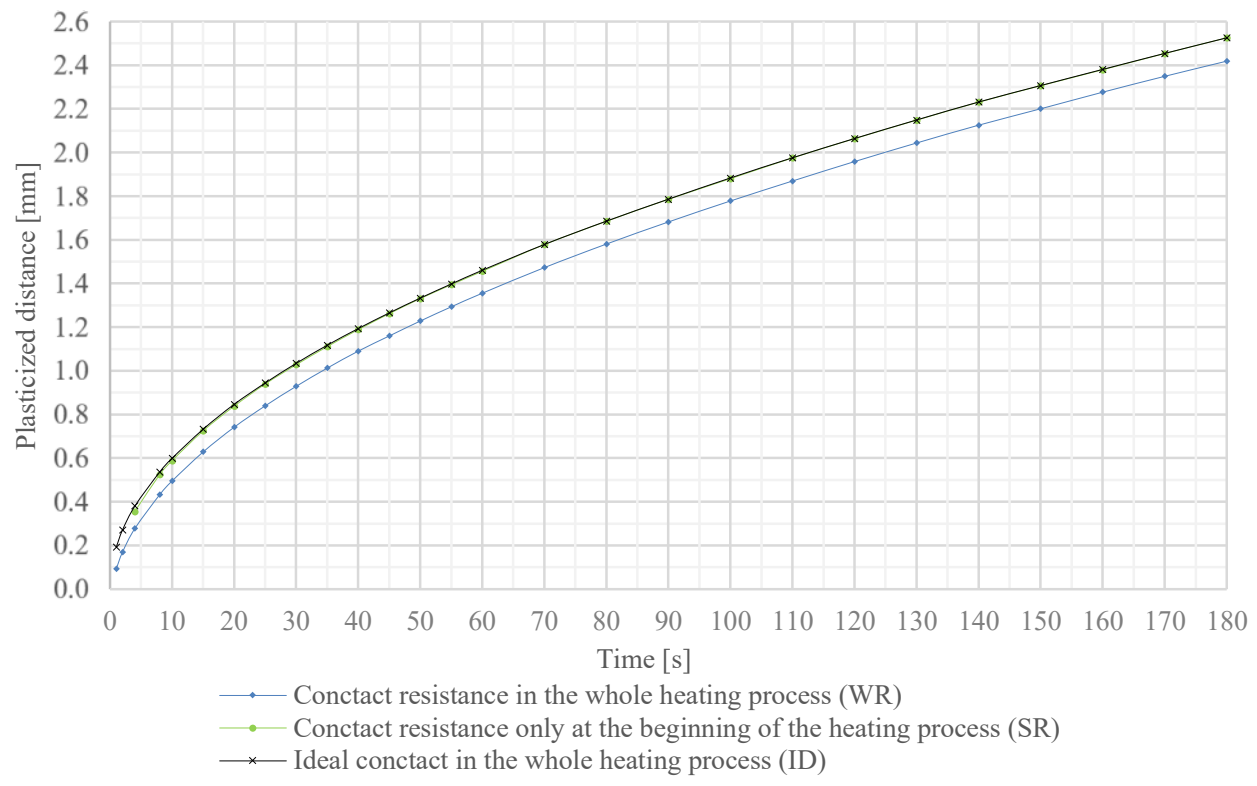

Fig. 6. Relationship between the depth of plastic region (plasticized distance) and the heating time

The numerical values of the depth of the plastic region and the percentage decrease in relation to perfect thermal contact conditions (ID) are given in Table 2 below.

The depth of plastic region will not change (in relation to the perfect thermal contact conditions - ID) if thermal contact resistance is limited to the initial heating time lasting not longer than $70 \mathrm{sec}$ (SR). Conversely, with thermal contact resistance assumed to persist throughout the whole heating period (case WR) the decrease in the depth of plastic region is prominent and present throughout the whole heating period.

Table 2. The numerical values of the depth of the plastic region for three different thermal contact conditions

\begin{tabular}{c|c|c|c|c|c}
\hline & ID & \multicolumn{2}{|c|}{ SR } & \multicolumn{2}{c}{ WR } \\
\hline Time [sec.] & Value [mm] & Value [mm] & Decrease [\%] & Value [mm] & Decrease [\%] \\
\hline 4 & 0.380 & 0.355 & 6.6 & 0.278 & 26.8 \\
\hline 8 & 0.536 & 0.524 & 2.3 & 0.433 & 19.2 \\
\hline 10 & 0.599 & 0.588 & 1.9 & 0.496 & 17.2 \\
\hline$\cdot$ & $\cdot$ & $\cdot$ & $\cdot$ & $\cdot$ & $\cdot$ \\
$\cdot$ & $\cdot$ & $\cdot$ & $\cdot$ & $\cdot$ & $\cdot$ \\
\hline 50 & 1.333 & 1.331 & 0.1 & 1.228 & 7.8 \\
\hline 55 & 1.397 & 1.394 & 0.2 & 1.293 & 7.4 \\
\hline 60 & 1.460 & 1.456 & 0.3 & 1.356 & 7.2 \\
\hline 70 & 1.578 & 1.578 & 0.0 & 1.473 & 6.7 \\
\hline 80 & 1.685 & 1.685 & 0.0 & 1.581 & 6.2 \\
\hline 90 & 1.786 & 1.786 & 0.0 & 1.682 & 5.8 \\
\hline$\cdot$ & $\cdot$ & $\cdot$ & $\cdot$ & $\cdot$ & $\cdot$ \\
$\cdot$ & $\cdot$ & $\cdot$ & $\cdot$ & $\cdot$ & $\cdot$ \\
\hline 170 & 2.453 & 2.453 & 0.0 & 2.349 & 4.2 \\
\hline 180 & 2.525 & 2.525 & 0.0 & 2.419 & 4.2 \\
\hline
\end{tabular}




\section{Conclusions}

The results of calculations and simulations show that selection of an appropriate thermal contact heat transfer model is of key importance for correct determination of the temperature distribution and the depth of plastic region during the heating process.

The temperature distribution and, as a consequence, also the depth of the plastic region vary significantly between the model assuming thermal contact resistance between the belt and the hot plate throughout the whole process and the model assuming perfect thermal contact conditions (ID). Therefore, the efficiency of the heating process would be affected in the former case. This can result from emission of gasses during melting when the plastic is heated up with a too hot plate (resulting in thermal destruction of the material).

With thermal contact resistance limited to the initial phase of the heating process (for example till the plastic region has reached the depth of $p=0.2 \mathrm{~mm}$ ) it does not influence the plastic region determination if the heating time duration is long enough, i.e. longer than $70 \mathrm{sec}$. which holds for the thermal contact resistance conductance values given in Table 1. This being so, for longer heating time periods perfect thermal contact conditions can be assumed for the whole process in this case.

It is finally concluded that increasing the heating time is not an efficient way to increase the depth of the plastic region (plasticized distance).

\section{References}

1. D. Wojtkowiak, K. Talaśka, I. Malujda, G. Domek, Analysis of the influence of the cutting edge geometry on parameters of the perforation process for conveyor and transmission belts. MATEC Web of Conferences 157: 01022 (2018)

2. K. Talaśka, D. Wojtkowiak, Modelling a mechanical properties of the multilayer composite materials with the polyamide core. MATEC Web of Conferences 157: 02052 (2018)

3. D. Wojtkowiak, K. Talaśka, I. Malujda, G. Domek, Estimation of the perforation force for polymer composite conveyor belts taking into consideration the shape of the piercing punch. The International Journal of Advanced Manufacturing Technology (2018) https://doi.org/10.1007/s00170-018-2381-3

4. P. Krawiec, A. Marlewski, Profile design of noncircular belt pulleys. Journal of Theoretical and Applied Mechanics 54 (2), 561-570 (2016)

5. P. Krawiec, A. Marlewski, Spline description of non-typical gears for belt transmissions. Journal of Theoretical and Applied Mechanics 49 (2), 355-367 (2011)

6. G. Domek, A. Kołodziej, M. Dudziak, T. Woźniak, Identification of the quality of timing belt pulleys. Procedia Engineering 177, 275-280 (2016)

7. M. Kukla, P. Tarkowski, J. Górecki, I. Malujda, K. Talaśka, The Effect of Magnetic Field on Magnetorheological Composites. Artificial Neural Network Based Modelling and Experiments. Applied Mechanics and Materials 816, 327-336 (2015)

8. Behabelt, Product Catalogue 2015/2016, Behabelt, Glotteral, (2015)

9. K. Wałęsa, I. Malujda, K. Talaśka, Butt welding of round drive belts. Acta Mechanica et Automatica 12 (2), 115-126 (2018)

10. R. Sikora, Przetwórstwo tworzyw wielkocząsteczkowych, Wydawnictwo Żak, Warszawa (1993)

11. N. Amanat, N. L. James, D.R. McKenzie, Welding methods for joining thermoplastic polymers for the hermetic enclosure of medical devices. Medical Engineering \& Physics 32, 690-699 (2010)

12. D. Grewell, A. Benatar, Welding of Plastics: Fundamentals and New Developments. International Polymer Processing 22 (1): 43 - 60 (2007) 
13. M. Troughton (eds.), Handbook of Plastics Joining: A practical guide. Plastics Design Library, New York (1997)

14. A. Mokhtarzadeh, A. Benatar, Experiments with conventional and high temperature hot plate welding of thermoplastics using temperature and pressure control. ANTEC 2012 Plastics: Annual Technical Conference Proceedings, 1684-1690 (2012)

15. A. Mokhtarzadeh, $\mathrm{Ch}$. Wu, A. Benatar, Comparison of hot plate and vibration welding of PMMA to ABS. ANTEC 2008 Plastics: Annual Technical Conference Proceedings, $856-861(2008)$

16. C. Krishnan, A. Benatar, Analysis of Residual Stress in Hot Plate Welded Polycarbonate. ANTEC 2004 Plastics: Annual Technical Conference: Processing (1), 1149 - 1153 (2004)

17. J. Nieh, J. Lee, Hot Plate Welding of Polypropylene Part I: Crystallization Kinetics. Polymer Engineering and Science 38 (7), 1121 - 1132 (1998)

18. BASF, Thermoplastic Polyurethane Elastomers, Elastollan ${ }^{\circledR}-$ Material Properties. BASF Material Brochure (2010)

19. K. Wałęsa, I. Malujda, K. Talaśka, Experimental research of round welded drive belts. Mechanik 5-6, 443-446 (2018)

20. H. Potente, J. Schneiders, M. Bornemann, Theoretical model for the one-dimensional temperature and stress calculation of simple hot plate welded geometries. Macromolecular Materials and Engineering 287, 843-853 (2002)

21. A. Klimpel, Spawanie $i$ zgrzewanie tworzyw termoplastycznych. Wydawnictwo Politechniki Śląskiej, Gliwice (2000)

22. K. Wałęsa, I. Malujda, K. Talaśka, M. Pietrzak, D. Wilczyński, Process analysis of hot plate welding of drive belts. Machine Dynamics Research, (2018, in press)

23. M. Cocard, I. Grozav, M. Iacob, A. Caneparu, Establishing the optimum welding procedure for PE 100 Polyethylene pipelines using the response surface design. Materiale Plastice 46, 452-457 (2009)

24. K. Wałęsa, O. Mysiukiewicz, M. Pietrzak, J. Górecki, D, Wilczyński, Preliminary research of the thermomechanical priperties of the round drive belts. MATEC Web of Conferences (2018 - in press)

25. M. F. Ashby, D. R. H. Jones, Materiaty inżynierskie. WNT, Warszawa (1996)

26. L. Wanqing, F. Changqing, Z. Xing, C. Youliang, Y. Rong, L. Donghong, Morphology and thermal properties of polyurethane elastomer based on representative structural chain extenders. Thermochimica Acta 653, 116-125 (2017)

27. H.S. Carslaw, J.C. Jeager, Conduction of Heat in Solids. Oxford University Press, London (1959)

28. S. T. Amoncio-Filho, J. F. dos Stantos, Joining of polymers and polymer-metal hybrid structures: recent developments and trends. Polymer Engineering and Science 49, 1461 1476 (2009)

29. Savija I., Culham J. R., Yovanovich M. M., Review of Thermal Conductance Models for Joints Incorporating Enhancement Materials. Journal of Thermophysics and heat transfer 17 (1), 43-52 (2003)

30. Parihar S. K., Wright N. T., Thermal contact resistance at elastomer to metal interfaces. International Communications in Heat and Mass Transfer 24 (8), 1083-1092 (1997)

31. A. Benada, A. Derdouri, M. Lamontagne, Y. Simard, Analysis of thermal contact resistance between polymer and mold injection molding. Applied Thermal Engineering 24, 2029-2040 (2004) 